\title{
THERMO-HYDRODYNAMICS PERFORMANCE ANALYSIS OF FLUID FLOW THROUGH CONCAVE DELTA WINGLET VORTEX GENERATORS BY NUMERICAL SIMULATION
}

\author{
Syaiful $^{*}$, Astrid Ayutasari ${ }^{1}$, Maria F. Soetanto ${ }^{2}$, Ahmad Indra Siswantara $^{3}$, Myung-whan Bae $^{4}$ \\ ${ }^{1}$ Department of Mechanical Engineering, Faculty of Engineering, Diponegoro University, $\mathrm{Jl}$. \\ Prof.Soedarto, Tembalang, Semarang 50275, Indonesia \\ ${ }^{2}$ Department of Aerospace, Polytechnic of Bandung, Jl. Kampus Polban, Ciwaruga, Parongpong, \\ Kabupaten Bandung Barat, West Java 40559, Indonesia. \\ ${ }^{3}$ Department of Mechanical Engineering, Faculty of Engineering, Universitas Indonesia, Kampus UI \\ Depok, Depok 16424, Indonesia \\ ${ }^{4}$ Engineering Research Institute, Department of Mechanical Engineering for Production, Gyeongsang \\ National University, 501, Jinju-daero, Jinju, Gyeongsangnam-do, 660-701, South Korea
}

(Received: November 2016 / Revised: May 2017 / Accepted: October 2017)

\begin{abstract}
The numerical simulation of heat transfer and pressure drop characteristics was carried out on the airflow through a rectangular channel-mounted vortex generator (VG). The VG was installed on a plate that was attached to the heater. The inlet velocity of the airflow varied from 0.4 to $2.0 \mathrm{~m} / \mathrm{s}$. The VGs used in this study were concave delta winglet pairs (CDWPs) with the attack angle of $30^{\circ}$ and with variation in the number of rows: one pair, two pairs, and three pairs. The CDWPs are predicted to produce the longitudinal vortex (LV), which increases the intensity of turbulence resulting in better mixing of flow. This, in turn, can improve the heat transfer between the plate surface and the airflow in the rectangular channel. The results showed that the installation of CDWPs does improve the overall heat transfer performance. However, it has the consequences of a greater pressure drop. Based on the variation in the number of rows, the greater the number of pairs of VGs was the greater the convection heat transfer coefficient (h) in both laminar and turbulent flows. The $h$ value was based on the number of row of CDWPs: one pair, two pairs, and three pairs exhibited increases of 65.9-108.4\%; 34.4-71\%; and 42.2-110.7\% compared to the baseline, respectively. A great number of rows of VGs also led to an increasing pressure drop value in laminar and turbulent flows. The percentage increases in pressure drop for CDWPs with one pair, two pairs, and three pairs, as compared to the baseline, were $70.1-92.1 \%$; $123.6-161.3 \%$, and $180-266.9 \%$, respectively.
\end{abstract}

Keywords: Concave delta winglet; Convection coefficient of heat transfer; Longitudinal vortex; Pressure drop; Vortex generator

\section{INTRODUCTION}

Numerous studies have been conducted on various Heat Transfer Enhancement technologies with the aim of improving the performance and reducing the heat exchanger size and resources or the cost of heat exchanger equipment. There are many ways to improve the efficiency of heat exchanger equipment. One method that can be used is to increase the contact surface of heat

*Corresponding author's email: syaiful.undip2011@gmail.com, Tel: +62-81228501462, Fax: +62-024-7460059

Permalink/DOI: https://doi.org/10.14716/ijtech.v8i7.706 
transfer, but this is limited to the size of heat exchanger used. In general, the dimensions of heat exchanger equipment are restricted by the availability of space. Therefore, researchers have begun to study other ways in which to improve thermal efficiency without the need to enlarge the size of the heat exchanger, namely by increasing the convection heat transfer coefficient. The higher the convection heat transfer coefficient, the higher the rate of heat transfer generated by the heat exchanger equipment. Increasing the rate of heat transfer is more effectively performed by using a passive technique that employ a vortex generator (VG) or turbulator. VGs have a prominent surface to be added to the main surface by means of embossing, punching, stamping, and attaching. Swirl flow can be generated when air passes through the VG (Fiebig, 1998).

The performance of a VG consists of three stages: (1) the formation of the boundary layer; (2) the emergence of swirl; and (3) flow destabilization (Fiebig, 1998). A VG enhances the mixing of the fluid, and damages the thermal boundary layer causing an increase in the average velocity and temperature gradients, thus increasing the convection heat transfer coefficient. Good mixing of flow results in better heat transfer.

Fiebig (1998) numerically and experimentally determined that the longitudinal vortex (LV) results in greater improvement in heat transfer than the transverse vortex for the same pressure loss penalty. Joardar and Jacobi (2008) experimentally investigated the characteristics of a heat exchanger with a delta winglet VG. They found that the air-side heat transfer was increased by $68 \%$ for 3 VG array arrangement. Torii et al. (2002) showed that the VG "common flow up" configuration was effective in reducing the pressure drop in the flow of fin-tube heat exchangers at low Reynolds numbers. He et al. (2013) investigated the characteristics of fluid flow and heat transfer numerically on the air side of the wavy fin-tube heat exchanger with an added three rows of delta winglet VG arranged in inline and staggered. Their work informed that staggered array of VG was better than inline array in improvement of pressure loss penalty without reducing the heat transfer enhancement. Khoshvaght-Aliabadi et al. (2015) conducted an experiment on the heat transfer and pressure drop in a tube which had 14 delta winglet VGs attached in a variety of mounting configurations. They described that the use of the VG inserted inside the tube yielded higher heat transfer and pressure drop. Meanwhile, Saha et al. (2014) carried out an experiment using delta and rectangular winglet VGs arranged in "common flow up" and "common flow down" configurations to determine the effect of the geometry and arrangement of the VG on the local flow characteristics and heat transfer. They exhibited that rectangular winglet pair (RWP) is more effective in heat transfer enhancement as compared to delta winglet pair (DWP). Kamboj et al. (2014) performed CFD simulations of the hydrodynamic performance of a hollow trapezoidal VG. They found that the punched hole of VG enhanced heat transfer and reduced flow resistance. Wu and Tao (2008) numerically and experimentally investigated the effects of the size, shape, and location of LVGs on heat transfer and flow resistance in a rectangular channel. They analyzed heat transfer improvement from view point of field synergy principle. They defined LV improving the synergy between velocity and temperature field.

Syaiful et al. (2017) experimentally investigated the effects of a concave rectangular winglet pair (CRWP) VG on heat transfer improvement in the airflow inside a rectangular channel. The results showed that the rate of heat transfer increased by up to $205 \%$ at the highest flow rate, but a substantial increase in pressure drop was also found. The current study continues the work undertaken by these authors. However, the present work is focused on using concave delta winglet pairs (CDWPs) rather than CRWP VGs. Therefore, this work aims to investigate the thermal and hydrodynamic performances of fluid flow through CDWPVGs. 


\section{EXPERIMENTAL SET UP AND MODELING}

The experiment has been carried out to validate the numerical calculation. A schematic of the experimental set up for this study can be seen in Figure 1. The computation domain of this numerical simulation was based on the physical phenomena in the experiment. Some thermocouples were mounted in several locations. Six thermocouples were placed $20 \mathrm{~mm}$ behind each VGs. A blower with a motor regulator determined the air capacity flowing in the channel. A straightener was set upstream of the test section (a flat plate with and without VGs, which was heated by a heater) to obtain a uniform flow. A hot wire anemometer (Lutron AM4204, resolution of $0.1 \mathrm{~m} / \mathrm{s}$ ) was set close to the straightener in order to monitor the inlet velocity of airflow. A heater with a constant heat rate of $35 \mathrm{~W}$ was induced behind the flat plate (using a wattmeter). Six thermocouples (K-type with an accuracy of $0.75 \%$ ) were mounted in the test section streamwise to measure surface temperatures. Data acquisition was achieved by converting the analog temperature data into digital data, which was then read and saved to a computer. A micro-manometer (Fluke 922 pitot tube with an accuracy of 1\%) was set to measure the pressure drop of the air flowing through the test section. Three green laser pens set a certain distance apart were each induced through the glass cylinder to form a cross section to capture the LV formed in the flow. A camera was set up at three different locations to monitor flow visualization. A compressor was used to push the smoke out of the dye injector.

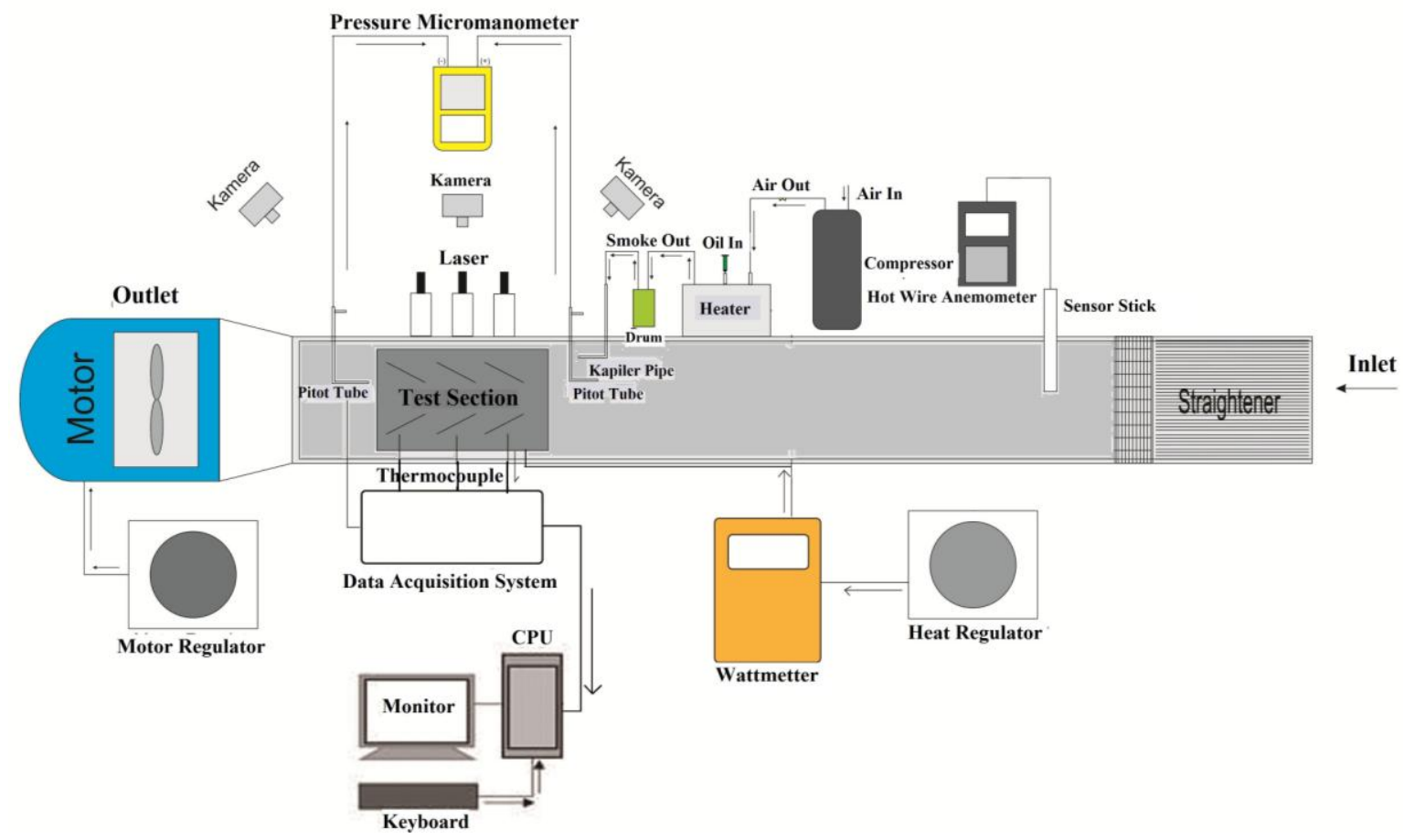

Figure 1 Schematic diagram of experimental set up

The test section streamwise to measure surface temperatures. Data acquisition was achieved by converting the analog temperature data into digital data, which was then read and saved to a computer. A micro-manometer (Fluke 922 pitot tube with an accuracy of 1\%) was set to measure the pressure drop of the air flowing through the test section. Three green laser pens set a certain distance apart were each induced through the glass cylinder to form a cross section to capture the LV formed in the flow. A camera was set up at three different locations to monitor flow visualization. A compressor was used to push the smoke out of the dye injector. 
The computation domain of this numerical simulation was based on the physical phenomena in the experiment. Some thermocouples were mounted in several locations. Six thermocouples were placed $20 \mathrm{~mm}$ behind each VGs. A blower with a motor regulator determined the air capacity flowing in the channel. A straightener was set upstream of the test section (a flat plate with and without VGs, which was heated by a heater) to obtain a uniform flow. A hot wire anemometer (Lutron AM-4204, resolution of $0.1 \mathrm{~m} / \mathrm{s}$ ) was set close to the straightener in order to monitor the inlet velocity of airflow. A heater with a constant heat rate of $35 \mathrm{~W}$ was induced behind the flat plate (using a wattmeter). Six thermocouples (K-type with an accuracy of $0.75 \%$ ) were mounted in the test section streamwise to measure surface temperatures. Data acquisition was achieved by converting the analog temperature data into digital data, which was then read and saved to a computer. A micro-manometer (Fluke 922 pitot tube with an accuracy of $1 \%$ ) was set to measure the pressure drop of the air flowing through the test section. Three green laser pens set a certain distance apart were each induced through the glass cylinder to form a cross section to capture the LV formed in the flow. A camera was set up at three different locations to monitor flow visualization. A compressor was used to push the smoke out of the dye injector.

\subsection{Modeling}

\subsubsection{Geometry configuration and computation domain}

The geometry configuration, as shown in Figure 2 was used as a reference for the computation domain. The computation domain consisted of four cases, which were baseline, one row of VGs, two rows of VGs, and three rows of VGs. Figure 3 depicts the computation domain for the case of three rows of VGs. Symmetry conditions were used such that only half of the computation domain was required for each case, thereby saving time.
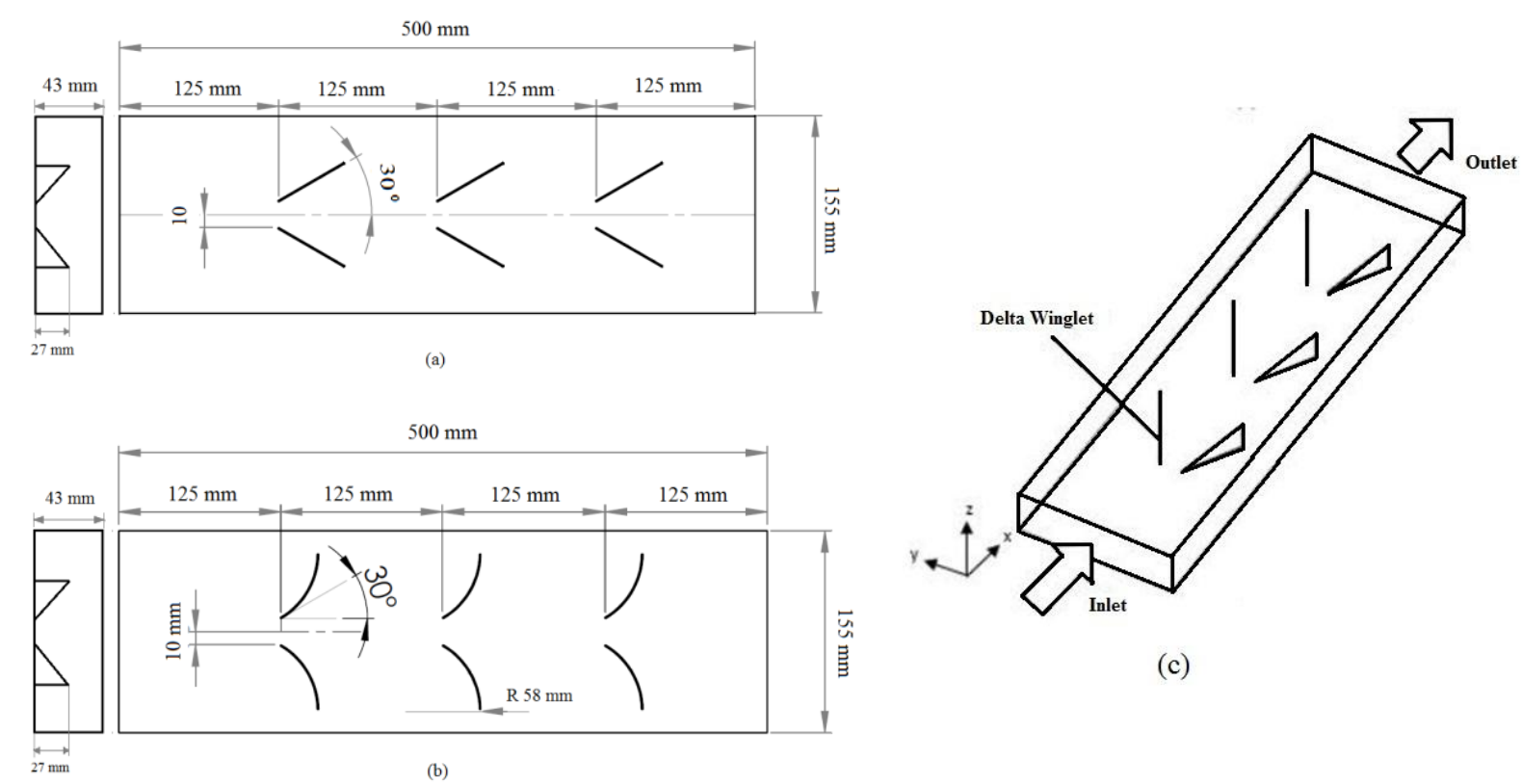

Figure 2 Geometry computation domain: (a) Three rows of DWP VG; (b) Three rows of CDWP VG; and (c) "common flow up" DWP 


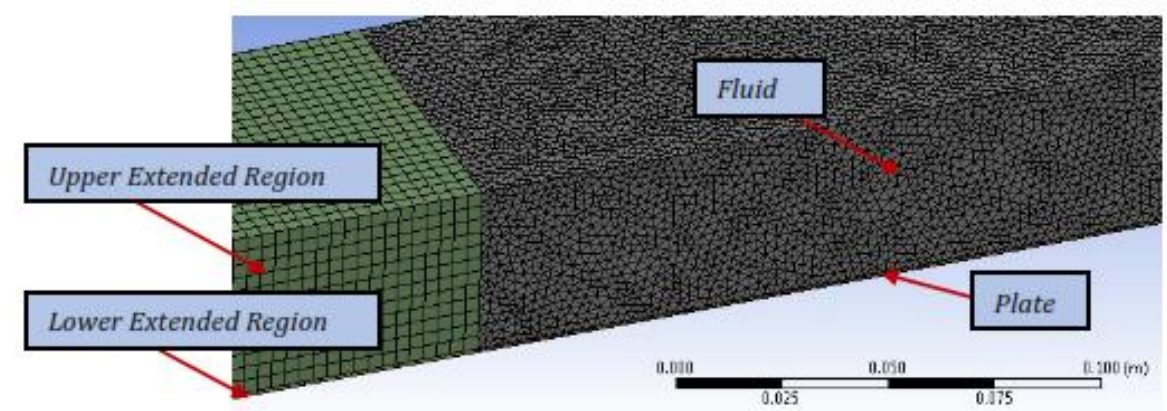

Figure 3 Mesh generation of computational domain

\subsubsection{Mathematical model}

The governing equations used in this numerical simulation were mass, momentum and energy conservations, respectively, as given below:

$$
\begin{gathered}
\frac{\partial}{\partial x_{i}}\left(\rho u_{i}\right)=0 \\
\frac{\partial}{\partial x_{i}}\left(\rho u_{i} u_{k}\right)=\frac{\partial}{\partial x_{i}}\left(\eta \frac{\partial u_{k}}{\partial x_{i}}\right)-\frac{\partial p}{\partial x_{k}} \\
\frac{\partial}{\partial x_{i}}\left(\rho u_{i} T\right)=\frac{\partial}{\partial x_{i}}\left(\frac{\lambda}{c_{p}} \frac{\partial T}{\partial x_{i}}\right)
\end{gathered}
$$

In order to calculate the turbulent model, the k- $\omega$ standard turbulent model was used. The k- $\omega$ standard turbulent model consists of a transport equation of turbulence kinetic energy $(\mathrm{k})$,

$$
\frac{\partial}{\partial t}(\rho k)+\frac{\partial}{\partial x_{i}}\left(\rho k u_{i}\right)=\frac{\partial}{\partial x_{j}}\left(\Gamma_{\mathrm{k}} \frac{\partial \mathrm{k}}{\partial \mathrm{x}_{\mathrm{j}}}\right)+G_{k}-Y_{k}+S_{k}
$$

and specific dissipation rate $(\omega)$,

$$
\frac{\partial}{\partial t}(\rho \omega)+\frac{\partial}{\partial x_{i}}\left(\rho \omega u_{i}\right)=\frac{\partial}{\partial x_{j}}\left(\Gamma_{\omega} \frac{\partial \omega}{\partial x_{j}}\right)+G_{\omega}-Y_{\omega}+S_{\omega}
$$

where $\Gamma_{k}=\mu+\mu_{t} / \sigma_{k}, \Gamma_{\omega}=\mu+\mu_{t} / \sigma_{\omega}, G_{k}=-\rho \overline{u_{k} u_{j}} \partial u_{j} / \partial x_{i}, G_{\omega}=\alpha \omega / k G_{k}, \alpha$ for this case is equal $1, Y_{k}=\rho \beta^{*} f_{\beta^{*}} k \omega$, and $Y_{\omega}=\rho \beta^{*} f_{\beta^{*}} \omega^{2}$.

\subsubsection{Boundary conditions}

The following boundary conditions were required to solve mathematical model.

- Inlet boundary conditions:

$$
u=u_{\text {in }}, v=w=0, T=T_{\text {in }}, I=0.16 R e_{D_{H}}^{-1 / 8}
$$

- Outlet boundary conditions:

$$
\frac{\partial u}{\partial x}=\frac{\partial v}{\partial x}=\frac{\partial w}{\partial x}=\frac{\partial T}{\partial x}=0
$$

- Side and top boundary conditions:

$$
u=v=w=0, q=0
$$


- Bottom wall boundary conditions:

$$
u=v=w=0, T=T_{w}
$$

- Symmetry boundary conditions:

$$
w=0, \frac{\partial u}{\partial y}=\frac{\partial w}{\partial y}=\frac{\partial T}{\partial y}=0
$$

At the LVG surface, no slip boundary condition was imposed.

\subsection{Numerical Method}

Grid independence was obtained. The grid independence test aims to ensure that the numerical simulation results are not influenced by the number of mesh elements. 1.661 .610 was selected as grid independence. In order to generate the mesh, the computational domain in the inlet and outlet was extended to achieve fully developed flow in the inlet and to overcome reverse flow in the outlet. A tetrahedral mesh was used in the computational domain, while a hexahedral mesh was used for the upstream and downstream extended regions, as shown in Figure 3.

In this study, the calculation was performed at the steady state condition with incompressible flow. The second upwind differencing scheme was used to discretize the momentum, energy, turbulent kinetic energy, and specific dissipation rate. The coupling between velocity and pressure was performed by using the SIMPLE algorithm. The convergent criterion was $10^{-5}$ for momentum, $10^{-8}$ for energy, and $10^{-6}$ for $\mathrm{k}-\omega$ equations.

\subsection{Parameter Definitions}

Several parameters, namely the Reynolds number, Nusselt number and convection coefficient, are given as:

$$
R e=\frac{\rho u_{i n} D_{H}}{\mu}, \quad \overline{N u}=\frac{q}{A\left(T_{w}-T_{f}\right)} \frac{2 H}{\lambda} \text { and } \bar{h}=\frac{\overline{N u} \lambda}{2 H}
$$

The properties of the fluid were calculated at the film temperature and average temperature, as shown in Equation 12.

$$
T_{f}=\frac{\bar{T}_{\text {in }}+\bar{T}_{\text {out }}}{2}, \bar{T}=\frac{\iint_{A} u T d A}{\iint_{A} u d A}
$$

The pressure loss penalty for the airflow passing through the flat plate with and without VGs was determined by Equation (13).

$$
\bar{p}=\frac{\iint_{A} p d A}{\iint_{A} d A}, \Delta P=\bar{P}_{\text {in }}-\bar{P}_{\text {out }}
$$

\section{RESULTS AND DISCUSSION}

\subsection{Thermal Performance}

In this study, the results of the simulation were compared with the experimental results for the baseline case and the cases with one, two, and three pairs of DW VGs at various inlet velocities of air, as can be seen in Figure 4. From the results of the simulation and experiment illustrated in Figure 4, a similar tendency is found in both cases with and without the use of DWP VGs. 


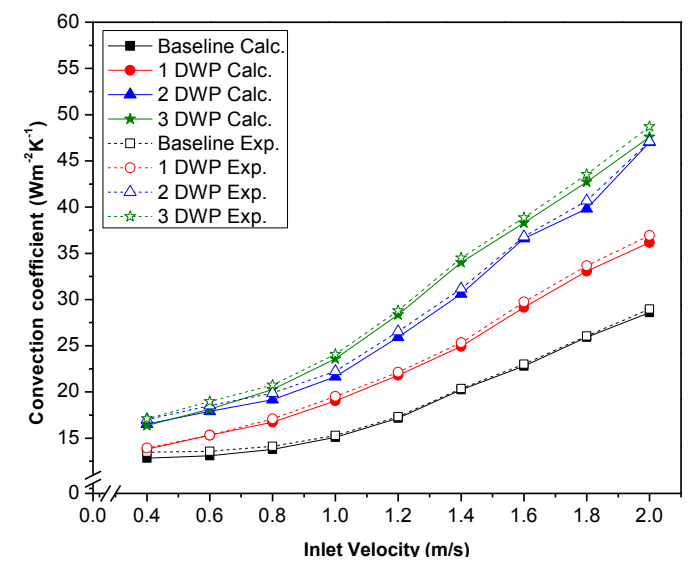

Figure 4 Convection coefficient values for DWP VGs in various inlet velocities

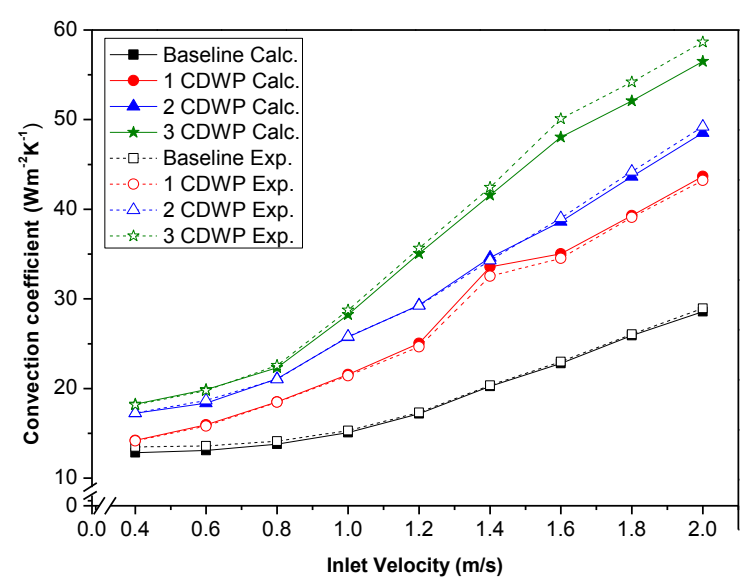

Figure 5 Convection coefficient values for CDWP VGs in various inlet velocities

The difference between the convection coefficient values for the simulation and experiment is relatively small: less than $6 \%$. Based on the results of the simulation and experiment, the convection coefficient increases with increasing inlet velocity. Mounting one to three pairs of DWP VGs causes the convection coefficient to increase by between $7.7 \%$ and $27.5 \%$ against the baseline at an inlet velocity of $0.4 \mathrm{~m} / \mathrm{s}$, while at an inlet velocity of $2 \mathrm{~m} / \mathrm{s}$, the convection coefficient increases by $26.5 \%$ to $66.5 \%$ against the baseline. The increase in convection coefficient is due to the emergence of LVs generated by the DWP VGs, which results in good mixing of the hot and cold fluids (Sarangi \& Mishra, 2017).

When using CDWP VGs, the convection coefficient augmentation is greater than that of DWP VGs, due to a larger radius of LVs as a result of centrifugal instability (Görtler, 1954; Malatesta et al., 2015). As shown in Figure 5, the convection coefficient increases by $10.8 \%$ to $42.2 \%$ against the baseline when one to three CDWP VGs are mounted at an inlet velocity of $0.4 \mathrm{~m} / \mathrm{s}$. At an inlet velocity of $2 \mathrm{~m} / \mathrm{s}$, the convection coefficient increases by $52.8 \%$ to $97.6 \%$ against the baseline when one to three CDWP VGs are mounted. For laminar flow (entry velocity of 0.4 $\mathrm{m} / \mathrm{s}$ ), the increase in heat transfer resulting from the use of a pair of CDW VGs is $2.9 \%$ higher than from the use of a pair of DW VGs. The use of two and three pairs of CDW VGs causes an increase in the convection coefficient that is, respectively, $4.3 \%$ and $11.5 \%$ higher than that of the CDW VGs. This is caused by the LVs generated by CDWP VGs being stronger and larger in diameter than those generated by the DWP VGs, as shown in Figure 6. The stronger and larger LVs cause more disturbance and secondary flow, resulting in stronger and wider flow mixing, which, in turn, produces better heat transfer augmentation (Xia et al., 2014). This improvement of heat transfer can also be identified by the increase in the local convection coefficient of heat transfer.

\subsection{Hydrodynamic Performance}

Figure 6 shows a comparison of pressure losses from the numerical simulation and experimental results. Despite the fairly large deviation for certain data between the results of the simulation and the experimental results, similar tendencies can be observed. As can be seen in Figure 6, pressure loss increases with increasing inlet velocity. For the baseline case, the experimental results find that the pressure losses at the inlet velocities of $0.4 \mathrm{~m} / \mathrm{s}$ to $0.8 \mathrm{~m} / \mathrm{s}$ are very small (zero as recorded by using the micro-manometer). This is due to the pressure loss value being below the minimum limit of the micro-manometer. However, the numerical simulation is able to calculate the pressure loss at the inlet velocities of 0.4 to $0.8 \mathrm{~m} / \mathrm{s}$ that could not be measured by the micro-manometer. Pressure loss increases with increasing inlet velocity 
for all cases (Fiebig, 1998; He et al., 2013). The increase in pressure loss at increasing inlet velocity is caused mainly by the addition of the formed drag force (He et al., 2013). Pressure loss obtained from the simulation is increased by $6.5 \%, 15.9 \%$ and $26.1 \%$ against the baseline at an inlet velocity of $0.4 \mathrm{~m} / \mathrm{s}$ when one, two, and three DWP VGs, respectively, are mounted on the test plate. At an inlet velocity of $2 \mathrm{~m} / \mathrm{s}$, pressure loss increases by $19.2 \%$ to $42.6 \%$ against the baseline case when one to three DWP VGs are mounted.

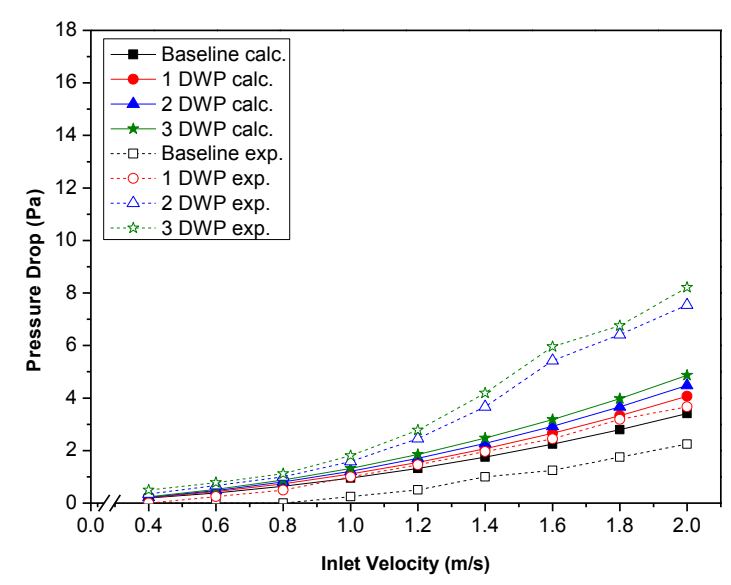

Figure 6 Pressure drop values for DWP VGs in various inlet velocities

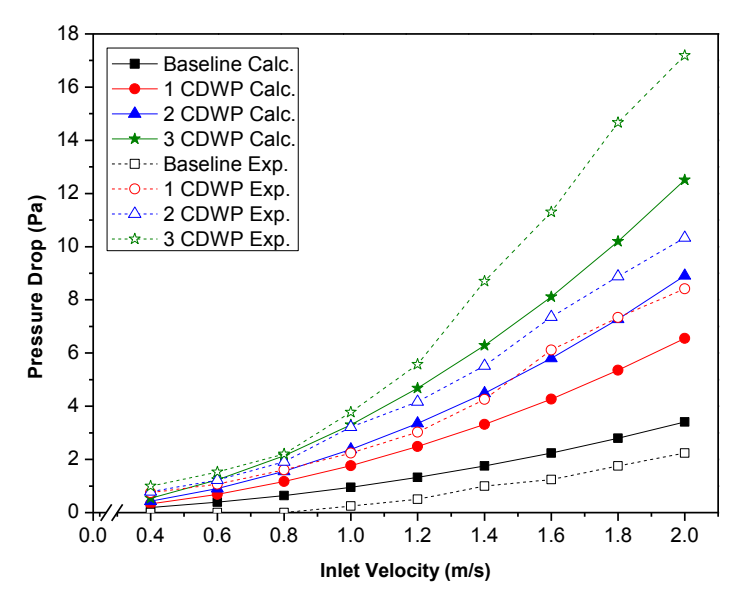

Figure 7 Pressure drop values for CDWP VGs in various inlet velocities

Figure 7 illustrates the value of the pressure loss for various inlet velocities without and with CDWP VGs according to the results of the experiment and numerical simulation. A good agreement between the numerical simulation and experimental results is found as shown in Figure 6. A similar tendency is observed by comparing Figures 6 and 7, and a similar trend is shown between the numerical simulation and experimental results. Based on the numerical simulation results, pressure losses for the cases with the use of one to three CDWP VGs are increase by $70.1 \%$ to $180 \%$ against the baseline at the inlet velocity of $0.4 \mathrm{~m} / \mathrm{s}$, while these increase by $92.1 \%$ to $266.8 \%$ at the inlet velocity of $2 \mathrm{~m} / \mathrm{s}$. The greater pressure loss resulting from the use of CDWP VGs than that of DWP VGs is caused by the wider areas of the CDWP VG surface pulverized by the air flow than that of the DWP VG. The increase in inlet velocity results in the increase in pressure loss penalty. This is caused by the presence of LVs and the complex interactions between the secondary flow and main flow (Ebrahimi et al., 2015).

\section{CONCLUSION}

A numerical simulation and experiments evaluating thermal and hydrodynamic performances have been carried out. Good agreement between the numerical simulation and experimental results has been found. The LV generated by the CDWP VG was stronger and wider than that of the DWP VG, resulting in greater improvement of heat transfer. This was probably caused by the centrifugal instability manifested when the fluid flowed over the concave wall. Unfortunately, the advantage of using a CDWP VG in improving heat transfer was accompanied by a greater increase in pressure drop than that exhibited in the use of the DWP VG.

\section{ACKNOWLEDGEMENT}

This work was supported by the Fundamental Research Project of Indonesia (KEMENRISTEK DIKTI Number 343-21/UN7.5.1/PP/2017). The authors are grateful to all research members, 
especially those of Lab. Thermofluid of Mechanical Engineering of Diponegoro University Indonesia, Aerospace Department of Polytechnic of Bandung Indonesia, Mechanical Engineering Department of University of Indonesia, and Advanced Combustion Lab. of Mechanical and Aerospace Engineering Faculty of Gyeongsang National University Korea.

\section{NOMENCLATURES}

a Turbulent viscosity coefficient

A Total area of heat transfer $\left(\mathrm{m}^{2}\right)$

CDWP Concave delta winglet pairs

$c_{p} \quad$ Specific heat of fluid $(\mathrm{J} /(\mathrm{kgK}))$

$\mathrm{D}_{\mathrm{h}} \quad$ Hydraulic diameter $(\mathrm{m})$

DWP Delta winglet pairs

$G_{k} \quad$ Generation of $k\left(\mathrm{~kg}^{2} /\left(\mathrm{m}^{4} \mathrm{~s}^{4}\right)\right)$

$G_{\omega} \quad$ Generation of $\omega\left(\mathrm{kg}^{2} /\left(\mathrm{m}^{4} \mathrm{~s}^{4}\right)\right)$

$H \quad$ Channel height (m)

$h \quad$ Convection coefficient $\left(\mathrm{W} /\left(\mathrm{m}^{2} \mathrm{~K}\right)\right)$

I Turbulent intensity (\%)

$k \quad$ Turbulent kinetic energy $\left(\mathrm{kg} /\left(\mathrm{ms}^{3}\right)\right)$

LVG Longitudinal vortex generators

$l_{\theta} \quad$ Entrance length (m)

$\mathrm{Nu} \quad$ Nusselt number

$P \quad$ Static pressure $(\mathrm{Pa})$

Re Reynolds number

$S_{k y} \quad$ User-defined source term $k\left(\mathrm{~kg}^{2} /\left(\mathrm{m}^{4} \mathrm{~s}^{4}\right)\right)$

$S_{\omega} \quad$ User-defined source term $\omega\left(\mathrm{kg}^{2} /\left(\mathrm{m}^{4} \mathrm{~s}^{4}\right)\right)$

$T \quad$ Temperature (K)

$u \quad$ Velocity in-x $(\mathrm{m} / \mathrm{s})$

VGs Vortex generators

$v \quad$ Velocity in-y $(\mathrm{m} / \mathrm{s})$

$w \quad$ Velocity in-z $(\mathrm{m} / \mathrm{s})$

$x, y, z \quad$ Cartesian coordinate
$Y_{k} \quad k$ dissipation due to turbulence $\left(\mathrm{kg}^{2} /\left(\mathrm{m}^{4} \mathrm{~s}^{4}\right)\right)$

$Y_{\omega} \quad \omega$ dissipation due to turbulence $\left(\mathrm{kg}^{2} /\left(\mathrm{m}^{4} \mathrm{~s}^{4}\right)\right)$

\section{Greek Symbols}

A Attack angle LVG $\left(^{\circ}\right)$

$\triangle P \quad$ Pressure drop (Pa)

$\lambda$ Thermal conductivity $(\mathrm{W} /(\mathrm{mK}))$

$\eta \quad$ Kinematic viscosity $\left(\mathrm{m}^{2} / \mathrm{s}\right)$

$\mu \quad$ Dynamic viscosity $(\mathrm{kg} /(\mathrm{ms}))$

$\mu_{t} \quad$ Turbulent viscosity $(\mathrm{kg} /(\mathrm{ms}))$

$\Omega \quad$ Specific dissipation rate $\left(\mathrm{kg} /\left(\mathrm{m}^{3} \mathrm{~s}^{2}\right)\right)$

$\rho \quad$ Density $\left(\mathrm{kg} /\left(\mathrm{m}^{3}\right)\right)$

$\sigma_{\omega} \quad$ Prandtl number of $\omega$

$\sigma_{k} \quad$ Prandtl number of $k$

$\Gamma_{k} \quad$ Diffusivity of $k(\mathrm{~kg} /(\mathrm{ms}))$

$\Gamma_{\omega} \quad$ Diffusivity of $\omega(\mathrm{kg} /(\mathrm{ms}))$

\section{Subscripts}

E Entrance

In Inlet

$i, k \quad$ Index

$\mathrm{m} \quad$ Mean average

out Outlet

w Wall

\section{REFERENCES}

Ebrahimi, A., Roohi, E., Kheradmand, S., 2015. Numerical Study of Liquid Flow and Heat Transfer in Rectangular Microchannel with Longitudinal Vortex Generators. Applied Thermal Engineering, Volume 78, pp. 576-583

Fiebig, M., 1998. Vortices, Generators and Heat Transfer. Trans IChemE, Volume 76, Part A, pp. $108-123$

Görtler, H., 1954. On the Three-dimensional Instability of Laminar Boundary Layers on Concave Walls. National Advisory Committee for Aeronautics, Technical Memorandum 1375, Washington, USA

He, Y.-L., Chu, P., Tao, W.-Q., Zhang, Y.-W., Xie, T., 2013. Analysis of Heat Transfer and Pressure Drop for Fin-and-tube Heat Exchangers with Rectangular Winglet-type Vortex Generators. Applied Thermal Engineering, Volume 61, pp. 770-783

Joardar, M., Jacobi, A.M., 2008. Heat Transfer Enhancement by Winglet-type Vortex Generator Arrays in Compact Plain-fin-and-tube Heat Exchangers. International Journal of Refrigeration, Volume 31, pp. 87-97 
Kamboj, R., Dhingra, S., Singh, G., 2014. CFD Simulation of Heat Transfer Enhancement by Plain and Curved Winglet Type Vertex Generators with Punched Holes. International Journal of Engineering Research and General Science, Volume 2(4), pp. 2091-2730

Khoshvaght-Aliabadi, M., Sartipzadeh, O., Alizadeh, A., 2015. An Experimental Study on Vortex-generator Insert with Different Arrangements of Delta-winglets. Energy, Volume 82, pp. 629-639

Malatesta, V., Souza, L.F., Joseph, T.C., Liu, Kloker, M.J., 2015. Heat Transfer Analysis Inaflow Over Concave Wall with Primary and Secondary Instabilities. Procedia IUTAM, Volume 14, pp. 487-495

Saha, P., Biswas, G., Sarkar, S., 2014. Comparison of Winglet-type Vortex Generators Periodically Deployed in a Plate-fin Heat Exchanger - A Synergy Based Analysis. International Journal of Heat and Mass Transfer, Volume 74, pp. 292-305

Sarangi, S.K., Mishra, D.P., 2017. Effect of Winglet Location on Heat Transfer of a Fin-andTube Heat Exchanger. Applied Thermal Engineering, Volume 116, pp. 528-540

Syaiful, Sugiri, G., Maria, F., Soetanto, Bae, M.-W., 2017. Effect of Concave Rectangular Winglet Vortex Generator on Convection Coefficient of Heat Transfer. In: AIP International Conference on Engineering, Science and Nanotechnology (ICESNANO), 1788

Torii, K., Kwak, K.M., Nishino, K., 2002. Heat Transfer Enhancement Accompanying Pressure-loss Reduction with Winglet-type Vortex Generators for Fin-tube Heat Exchangers. International Journal of Heat and Mass Transfer, Volume 45, pp. 3795-3801

Wu J.M. and Tao W.Q., 2008. Numerical study on laminar convection heat transfer in a rectangular channel with longitudinal vortex generator. Part A: Verification of field synergy principle. International Journal of Heat and Mass Transfer, Volume 51, pp. 11791191.

Xia, H.H., Tang, G.H., Shi, Y., Tao, W.Q., 2014. Simulation of Heat Transfer Enhancement by Longitudinal Vortex Generators in Dimple Heat Exchangers. Energy, Volume 74, pp. $27-$ 36 